Enlighten: Jurnal Bimbingan dan Konseling Islam

Vol. 2 No. 2 (July-December 2019), 112-121

http://dx.doi.org/10.32505/enlighten.v2i2.1363

\title{
Sasaran Dan Topik Pembahasan Self Disclosure Mahasiswa
}

Wan Chalidaziah ${ }^{1}$

${ }^{1}$ Program Studi Bimbingan dan Konseling Islam IAIN Langsa

${ }^{1}$ wan_chalidaziah@iainlangsa.ac.id

\begin{tabular}{ccc} 
First received: & Revised: & Final Accepted: \\
12 November 2019 & 06 December 2019 & 09 December 2019 \\
\hline
\end{tabular}

\begin{abstract}
The background of this research is the low self-disclosure of students in the College of Islamic Guidance and Counseling $X$. The purpose of this research are to explain of self-disclosure in Islamic Guidance and Counseling students with a review of the target and discussion topics. The Method was descriptive quantitative research. The research population was the students of guidance and counseling. The sample counsists of 122 students with Random Sampling technique. The research instrument used a Self Disclosure Scale with 54 statement items $(r=$ 0.91029). The Data analyzed by using descriptive. The result of determined that most student only give their information only in general, and some students have not been able to share their information with others. The results of this study also indicate that the significant person in self disclosure is the mother and the most open discussion topic on the topic of interests and tastes. Researchers suggest further action research in the form of training to improve self-disclosure given the importance of self-disclosure skills in student guidance and counseling.
\end{abstract}

Keywords: Self Disclosure, Topic, Student

\begin{abstract}
Abstrak
Penelitian ini dilatarbelakangi oleh rendahnya self disclosure yang ditampilkan oleh mahasiswa pada Prodi Bimbingan dan Konseling Islam Perguruan Tinggi X. Penelitian ini bertujuan untuk melihat bagaimana keadaan self disclosure pada mahasiswa Bimbingan dan Konseling Islam dengan tinjauan sasaran serta topik pembahasannya. Pendekan penelitian yang digunakan ialah jenis penelitian kuantitatif deskriptif. Populasi penelitian ini adalah mahasiswa bimbingan dan konseling islam dengan jumlah sample sebesar 122 mahasiswa melalui teknik random sampling. Instrumen penelitian menggunakan Skala Self Disclosure dengan 54 item pernyataan $(r=$ 0,91029). Data dianalisis menggunakan deskriptif. Temuan penelitian menunjukkan sebagian besar dari mahasiswa hanya menyampaikan informasi tentang dirinya secara garis besar saja, dan masih terdapat mahasiswa yang belum membuka informasi dirinya. Hasil penelitian ini juga menunjukkan bahwa sasaran pembukaan tertinggi berada pada posisi ibu dan topik pembahasan yang paling terbuka pada topik minat dan selera. Peneliti menyarankan tindakan lanjutan penelitian berupa pelatihan untuk peningkatan self disclosure mengingat pentingnya keterampilan self disclosure pada mahasiswa bimbingan dan konseling.
\end{abstract}

Kata Kunci: Self Disclosure, Sasaran, Topik Pembahasan, Mahasiswa

\section{PENDAHULUAN}

Proses konseling merupakan suatu hubungan yang sangat tergantung pada pola komunikasi. Sehingga kemampuan komunikasi interpersonal merupakan salah satu tuntutan yang perlu dimiliki oleh konselor dalam pelayanan konseling Cormier \& Cormier (1991). Self disclosure merupakan salah satu keterampilan konselor yang menuntut konselor untuk mampu menampilkan diri yang asli dan terbuka. Hal ini didukung oleh pendapat Jourard (1974) mengenai hubungan terapeutik yang penting dibangun oleh konselor melalui tingkah laku yang autentik dan terbuka, sehingga mampu mengajak konseli pada keautentikan karena self disclosure konselor yang spontan 
akan menunjang pertumbuhan self disclosure konseli.

Teknik yang digunakan konselor secara sadar dan sengaja untuk berbagi informasi mengenai kehidupannya di luar hubungan konseling disebut dengan self disclosure. Menurut Arlett, Littel \& Best (1976) self disclosure yang dimiliki konselor akan berpengaruh pada pribadi konseli. Kemudian Glading (2012) juga menjelaskan bahwa self disclosure dapat diartikan sebagai mengkondisikan diri agar diketahui orang lain, dengan cara mengungkapkan diri pribadi. Jourard (Glading, 2012) juga menjelaskan bahwa self disclosure konselor akan berguna dalam membangun rasa percaya dan memfasilitasi hubungan konseling.

Berdasarkan uraian tersebut, maka dapat dipahami bahwa self disclosure konselor dapat mempengaruhi pelaksanaan pelayanan bimbingan dan konseling. Sebagaimana Jourard (Corey, 2010) juga menjelaskan bahwa self disclosure konselor dapat membantu konseli dalam menemukan dirinya dan konselor harus membuka diri pada konseli disaat yang tepat. Self disclosure konselor yang dimaksud menurut Roger (Nelson-Jones, 2011) yaitu konselor berbagi perasaan tentang apa yang dirasakan konselor sebagai umpan balik yang diekspresikan dengan tulus. Self disclosure seperti ini dapat mempertahankan tingkat energi terapi dan memungkinkan konseli melihat bahwa mereka sedang berhadapan dengan manusia yang nyata. Sehingga Mcleod (2006) menjelaskan bahwa terapis humanis akan lebih cenderung menggunakan self disclosure dalam proses terapi.

Self disclosure merupakan suatu keterampilan konseling yang sangat penting dikuasai oleh mahasiswa. Ponzetti (1990) menjelaskan bahwa pentingnya self disclosure bagi mahasiswa terkait pada penghindaran perasaan kesepian. Sehingga dengan adanya kemahiran dalam keterampilan self disclosure dapat menciptakan rasa bahagia bagi mahasiswa yang merasa kesepian. Ifdil (2013) juga menjelaskan bahwa keterampilan self disclosure sangat penting untuk dimiliki oleh mahasiswa khususnya mahasiswa bimbingan dan konseling. Manfaat keterampilan self disclosure tidak sebatas untuk diri sendiri melainkan untuk keterampilan sebagai calon konselor. Namun masalahnya sebagai mahasiswa yang kerap menggunakan self disclosure sebagai keterampilan dasar yang marus di miliki, mmahasiswa bimbingan dan konseling masih belum memiliki self disclosure yang belum baik atau rendah, artinya mahasiswa belum mampu menyampaikan informasi mengenai dirinya kepada orang lain.

Sebagaimana temuan Daharnis, Nirwana, Ilyas \& Karneli (2002); Wei, Ressell \& Zakalik (2005); Sari, Rejeki \& Mujab (2006); Ifdil, Ardi, Barryyah, Hariko, \& Solina (2013) menemukan tingkat self disclosure mahasiswa bimbingan dan konseling cenderung berada pada kategori rendah. Sejalan dengan temuan tersebut Nirwana (2012) menyatakan bahwa konselor di sekolah belum menjadi significant person dan menjadi target person untuk mengungkapkan diri bagi siswasiswanya. Penemuan-penemuan diatas menyimpulkan bahwa keterampilan self disclosure mahasiswa masih dalam kategori rendah.

Permasalahan mengenai self disclosure mahasiswa bimbingan dan konseling yang cenderung rendah diprediksi merupakan akibat dari beberapa faktor yang mempengaruhi self disclosure mahasiswa. Jourard (1979); Hargie (2011: 263); DeVito (2012) menyebutkan beberapa faktor yang mempengaruhi sef disclosure ialah "Age, 
gender, ethnic and religious group, personality dan intoxication lavel". Berdasarkan kondisi tersebut maka dapat dimaknai bahwa terdapat lima faktor yang mempengaruhi keterbukaan diri individu yaitu (1) umur, (2) jenis kelamin, (3) budaya dan kelompok agama, (4) kepribadian, dan (5) level kesadaran. Kebudayaan dalam suatu masyarakat merupakan suatu faktor yang membentuk watak dan tingkah laku individu untuk mampu mengungkapkan diri dengan tepat atau justru membentuk individu yang sulit untuk mengungkapkan diri dan menjadi pribadi yang introvert. Lingkungan sosial dan budaya yang melatarbelakangi dan melingkupi individu berbeda-beda, sehingga meyebabkan perbedaan pula tingkat self disclosure yang dimiliki.

Sebagaimana temuan Nirwana (2012) dan Borae \& Hyun-Joo (2015) bahwa terdapat perbedaan self disclosure laki-laki dan perempuan dimana perempuan memiliki self disclosure yang lebih terbuka bila dibandingkan dengan self disclosure pada laki-laki. Namun penelitian ini tidak konsisten dengan penelitian Siagian (2016) dan Horne \& Matthew (2017) bahwa tidak terdapat perbedaan self disclosure bila ditinjau dari jenis kelamin. Perbedaan temuan ini mengindikasi bahwa terdapat faktor lain yang mempengaruhi perbedaan self disclosure mahasiswa salah satunya adalah faktor budaya.

Temuan di atas didukung Samovar, Porter, \& McDaniel (2010) bahwa budaya yang dibawa oleh laki-laki dan perempuan akan mempengaruhi self disclosure, dimana terdapat perbedaan perilaku antara lakilaki dan perempuan, laki-laki lebih kurang menyukai pembukaan diri dibandingkan perempuan pada umumnya. Pembawaan sifat laki-laki dan perempuan bisa saja berbeda-beda tergantung pada latar belakang budaya dan bentukan dari masyarakat. Myers (2012) menjelaskan bahwa sebagian besar perempuan memiliki keahlian khusus untuk terbuka, perempuan bisa saja mendapatkan keterbukaan secara intim dari orang lain meskipun ia tidak melakukan self disclosure yang begitu besar. Hal ini juga didukung oleh kecenderungan perempuan untuk menjadi pendengar yang baik dan mengungkapkan perasaan yang tepat pada lawan bicara. Tentunya hal ini berpengaruh pada self disclosure mahasiswa. Bagaimana keterampilan dan kebiasaan yang dimiliki oleh individu baik itu laki-laki maupun perempuan di dalam suatu budaya akan membedakan self disclosure.

Nilai-nilai kehidupan masyarakatnya sangat dipengauhi oleh budaya. Sebagimana Triandis (1994) menyatakan bahwa kebudayaan merupakan elemen subjektif dan objektif yang membuat perbedaan nilai antara satu kelompok dengan kelompok lain, termasuk didalamnya cara berkomunikasi. Budaya memiliki pengertuian yang sangat luas, termasuk nilai-ilai agama yang dimiliki individu Baharuddin (2007). Oleh sebab itu agama yang dimiliki akan mempengaruhi prilaku dari individu.

Mengacu pada permasalahan yang telah dipaparkan, maka tujuan umum penelitian ini adalah mendeskripsikan kondisi self disclosure mahasiswa dalam kehidupan sehari-hari serta melihat pembahasan yang sangat sering diungkapkan serta kepada siapa mahasiswa akan terbuka mengenai dirinya. Secara khusus penelitian ini bertujuan mendeskripsikan hal-hal sebagai berikut: (1) gambaran self disclosure mahasiswa (2) gambaran sasaran self disclosure mahasiswa. (3) gambaran topik pembahasan self disclosure mahasiswa

\section{METODE}


Penelitian menggunakan pendekatan kuantitatif dengan jenis deskriptif. Populasi dalam penelitian ialah mahasiswa bimbingan dan konseing Islam IAIN Langsa. Keseluruhan populasi berjumlah 175 mahasiswa dengan jumlah sampel sebesar 122 mahasiswa. Penarikan sampel penelitian menggunakan teknik Proportional Random Sampling. Instrumen yang digunakan pada penelitian ialah skala self disclosure dengan 54 item pernyataan ( $\mathrm{r}$ $=0,91029)$. Selanjutnya data dianalisis menggunakan teknik analisis melalui bantuan program SPSS versi 22 .

\section{HASIL TEMUAN}

Berdasarkan hasil pengolahan data penelitian ini maka dapat digambarkan sebagai berikut:

\section{1) Gambaran Self Disclosure Mahasiswa Secara Keseluruhan}

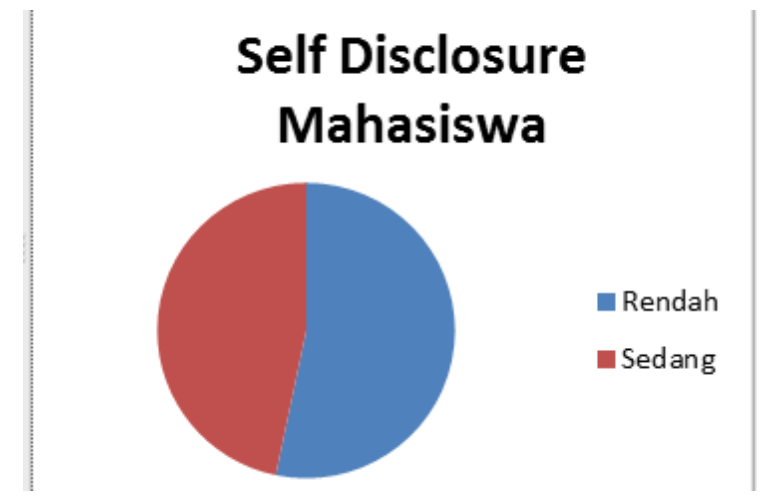

Hasil penelitian menunjukkan bahwa secara keseluruhan self disclosure mahasiswa bimbingan dan konseling islam berada dalam kategori Rendah. Hal ini dapat dilihat dari banyaknya mahasiswa yang memeiliki self disclosure dalam kategori rendah yaitu 65 dari 122 orang mahasiswa yang menjadi sample penelitian mempunyai self disclosure yang berada dalam kategori rendah atau mahasiswa belum menyampaikan informasi mengenai dirinya kepada orang lain dengan jumlah presentase 53,28\%. Dan hanya 57 orang mahasiswa mempunyai self disclosure dalam keadaan sedang atau mahasiswa hanya menyampaikan informasi mengenai diri secara garis besarnya saja dengan prsentase $38,5 \%$.

\section{2) Gambaran Self Disclosure Mahasiswa pada Sasaran Pembicaraan}

Hasil penelitian menunjukkan bahwa secara keseluruhan sasaran atau target person self disclosure mahasiswa bimbingan dan konseling islam yang menjadi tujuan utama yaitu ibu artinya mahasiswa akan sangat terbuka kepada ibu. Selanjutnya pada posisi kedua yaitu keterbukaan kepada ayah. Target person pada self disclosure yang ketiga ialah kepada teman sesama jenis, kemudian kepada teman lawan jenis dan target person yang terendah ialah kepada pacar. Pemaparan hasil penelitian ini dapat di lihat dari gambar dibawah yang menunjukkan bahwa mahasiswa akan lebih terbuka dalam menyampaikan informasi dirinya kepada Ibu dan akan sangat tertutup dalam menyampaikan informasi mengenai dirinya kepada pacar.

\section{3) Gambaran Self Disclosure mahasiswa pada topik pembahasan}

Hasil penelitian ini menunjukkan bahwa pada topik pembahasan tertinggi berada pada pembahasan mengenai pendidikan, pada posisi kedua terdapat pada topik selera dan minat kemudian dilanjutkan dengan topik mengenai sikap 
dan opini dan dilanjutkan pada urutan keempat pada topik pembahasan mengenai fisik. Pada topik pembahasan mengenai keuangan dan pada urutan terakhir pada topik pembahasan mengenai kepribadian. Pemaparan hasil penelitian ini dapat di lihat dari gambar dibawah yang menunjukkan bahwa mahasiswa lebih terbuka dalam menyampaikan informasi dirinya mengenai topik selera dan minat dan sangat tertutup pada topik mengenai kepribadian.

\section{PEMBAHASAN}

\section{1) Gambaran Self Disclosure Mahasiswa Secara Keseluruhan}

Hasil penelitian menunjukkan bahwa secara keseluruhan self disclosure mahasiswa secara keseluruhan berada pada kategori Rendah, artinya mahasiswa belum menyampaikan hal-hal yang berkenaan dengan dirinya secara terbuka kepada orang lain. Hasil penelitian yang menyatakan self disclosure mahasiswa berada dalam kategori rendah sejalan dengan temuan penelitian Daharnis, Nirwana, Ilyas \& Karneli, 2001; Nirwana 2012; Gusmawati, Taufik \& Ifdil, 2016 yang menyatakan tentang rendahnya kondisi self disclosure mahasiswa bimbingan dan konseling. Oleh sebab itu maka masih sangat dibutuhkan peningkatan keterampilan self disclosure pada mahasiswa khususnya mahasiswa bimbingan dan konseling islam yang menjadi sample penelitian ini.

Temuan mengenai rendahnya self disclosure mahasiswa ini mungkin dipengaruhi oleh beberapa faktor yang antar lain ialah budaya yang dimiliki oleh mahasiswa. Pernyataan ini sesuai dengan pernyataan bahwa budaya dari suatu kelompok akan mempengaruhi tingkah laku dan norma-norma yang dipegang oleh seseorang sehingga secara langsung akan mempengaruhi perilaku kelompok didalamnya termasuk cara berkomunikasi dan tata cara yang digunakan dalam berkomunikasi (Berry, Poortinga, Segall \& Dansen, 2002), Mulyana (2008). Latar belakang budaya yang dimiliki oleh mahasiswa secara langsung menyebabkan self disclosure mahasiswa rendah yang artinya latar belakang budaya mempengaruhi mahasiswa untuk dapat menyampaikan informasi dirinya dengan orang lain. Hal ini sesuai dengan penelitian Jourard (1979); Taylor, Peplau \& Sears, (1997); Tang, Bastman \& Hatpield (2013); Siagian (2016); Chalidaziah (2018) yang menyatakan bahwa rendahnya self disclosure mahasiswa dipengaruhi oleh budaya yang dan adat istiadat yang dimiliki dan melekat pada diri mahasiswa akan mempengaruhi seseorang dalam bertingkahlaku dan berkomunikasi.

Temuan mengenai rendahnya self disclosure mahasiswa ini juga di sebabkan oleh latar belakang budaya mahasiswa yang menjadi sampel penelitian sebahagian besar berlatar belakang budaya Melayu dan Aceh. Sebagaimana penelitian Sudjiman (1996); Soeleman (2015) juga menemukan bahwa orang Melayu sangat berhati-hati dalam berperilaku termasuk dalam mengekspresikan perasaannya sehingga dalam hubungan sehari-hari 
masyarakat Melayu tidak terlalu menunjukkan perasaan dan pandangannya secara keseluruhan pada orang lain karena akan dianggap sebagai individu yang kurang baik dalam lingkungan. Kebiasaan orang-orang Melayu yang menyimpan perasaan pribadinya ini menyebakan mereka dipandang kurang ekspresif dalam menunjukkan dirinya kepada orang lain.

Uraian diatas membuktikan bahwa temuan ini konsisten dengan temuan temuan sebelumnya bahwa self disclosure mahasiswa bimbingan dan konseling saat ini berada dalam kategori rendah, hal ini sangat perlu untuk ditingkatkan kareana keterampilan self disclosure sangat diperlukan bagi mahasiswa bimbingan dan konseling terlebih dalam proses konseling Ifdil (2013).

\section{2) Gambaran Self Disclosure Mahasiswa pada Sasaran Pembicaraan}

Temuan dalam penelitian mengenai self disclosure mahasiswa berdasarkan target person yaitu mahasiswa lebih terbuka kepada ibu hal ini karena ibu merupakan sosok penyayang, hal ini sependapat dengan Franzoi (2003) bahwa yang akan selalu ada saat anak-anaknya membutuhkan dan sosok yang memiliki perhatian penuh kepada anaknya sehingga anak akan cenderung terbuka kepada sosok ibu karena anak dan ibunya cenderung memiliki emosional yang sama sehingga membuat emosi yang dirasa lebih stabil. Tingginya self disclosure mahasiswa kepada ibunya juga pengaruhi oleh intensitas pertemuan yang lebih sering, sehingga dapat lebih leluasa dalam mengungkapkan perasaan dan pengalaman yang dimiliki Chalidaziah (2018).

Temuan lain dalam penelitian ini ialah temuan bahwa rendahnya self disclosure mahasiswa laki-laki kepada orang lain. Hal ini karena laki-laki cenderung untuk tidak menampakkan informasi mengenai diri kepada orang lain terlebih pada informasi yang bersifat negatif, pernyataan ini sesuai dengan pendapat Michener \& DeLamater (1999) bahwa kebanyakan laki-laki memandang terlalu banyak melakukan pengungkapan diri dianggap sebagai kelemahan. Rendahnya self disclosure laki-laki juga dilatarbelakangi tuntutan anak laki-laki yang sejak kecil dididik untuk mampu mengatasi masalahnya secara mandiri, bahkan rasa sakit yang ditampilkan bocah laki-laki dengan menangis telah dibatasi oleh orang tua dan dianggap sebagai perilaku manja dan cegeng. Kebiasaan ini terus dibawa oleh laki-laki hingga masa dewasa sehingga laki-laki akan mengabaikan keluhan penyakit ringan yang dideritanya dan baru akan kedokter apabila penyakit yang dideritanya telah sangat menganggu aktivitasnya.

Temuan ini juga menemukan bahwa mahasiswa akan cenderung terbuka dengan orang-orang yang memiliki hubungan dekat dengannya seperti ayah, dan teman sesama jenis hal ini dapat disebabkan oleh faktor hubungan dan pembangunan emosi (Taylor, Peplau \& Sears, 2006), dan juga dapat disebabkan oleh kenyamanan dalam berkomunikasi 
dengan sesama gender yang menyebabkan keterbukaan antar individu (Brehm, Miller, Perlman \& Campbell, 1992). Pernyataan tersebut akan mendukung temuan penelitian mngenai rendahnya self disclosure mahasiswa kepada lawan jenis dan pacar yang dipengaruhi oleh faktor lain yaitu budaya religius, terlebih sampel penelitian ini adalam mahasiswa bimbingan dan konseling islam. Dalam islam pola komunikasi memiliki ataruran tersendiri misalnya perempuan akan tertutup kepada teman laki-lakinya begitupun sebaliknya dan juga dengan pasangan atau pacar yang belum halal karena hal ini dianggap akan menimbulkan fitnah di mata masyarakat (Sutoyo, 2014 ).

\section{3) Gambaran Self Disclosure Mahasiswa pada Topik Pembicaraan}

Penelitian ini juga menemukan hasil dari rincian self disclosure mahasiswa berdasarkan aspek yang diungkapkan. Terdapat perbedaan tingkat hasil self disclosure mahasiswa dimana pada topik sikap, topik selera serta topik pendidikan akan lebih tinggi tingkat pengungkapan dirinya jika dibandingkan dengan topik keuangan, topik kepribadian dan topik fisik. Hal ini konsisten dengan temuan Daharnis, Nirwana, Ilyas, \& Karneli, 2002; Nirwana, 2012; Utz, 2015, Chalidaziah, 2018 memperlihatkan bahwa mahasiswa akan cenderung lebih tertutup pada aspek keuangan, aspek kepribadian dan aspek fisik dan akan lebih terbuka pada aspek sikap, aspek selera serta aspek pendidikan.
Tingginya self disclosure mahasiswa ini disebabkan karena pada penelitian ini sampel yang digunakan lebih banyak mahasiswa perempuan dari mahasiswa laki-laki sehingga menyebabkan aspek pendidikan dan keuangan lebih tinggi karena mahasiwa perempuan yang cenderung kurang memperoleh kebebasan untuk memilih keputusan (Nirwana, 2012). Pada aspek sikap mahasiswa perempuan juga lebih terbuka daripada aspek kepribadian dan fisik karena mahasiswa perempuan kurang bebas dalam menentukan sikapnya sehingga memerlukan orang tua dan teman dalam menentukan sikapnya. Pada aspek keuangan, tingginya self disclosure mahasiswa karena pada topik keuangan mahasiswa masih sangat bergantung pada orangtua, sementara hanya sebahagian kecil mahasiswa yang memiliki kemandirian dalam topik keuangan.

\section{SIMPULAN}

Berdasarkan hasil penelitian dan pembahasan yang telah dilakukan, maka penelitian ini dapat disimpulkan sebagai berikut:

1. Hasil penelitian ini menunjukkan bahwa secara keseluruhan self disclosure mahasiswa berada dalam kategori sedang, artinya mahasiswa belum terbuka mengenai informasi yang berkenaan dengan dirinya sehingga penting untuk meningkatkan keterampilan self disclosure mahasiswa. Self disclosure mahasiswa bimbingan dan 
konseling islam ini sangat penting untuk ditingkatkan.

2. Sasaran self disclosure mahasiswa bimbingan dan konseling islam yang paling utama tertuju kepada ibu artinya mahasiswa akan lebih terbuka mengenai informasi dirinya ialah kepada ibu. Ibu dijadikan mahasiswa sebagai tempat untuk berkeluh kesah dan tempat berbagi tentang pengalamannya.

3. Hasil penelitian juga menunjukkan bahwa topik pembahasan mahasiswa bimbingan dan konseling islam yang paling terbuka ialah mengenai selera dan minat artinya mahasiswa bimbingan dan konseling islam akan lebih terbuka dan menyampaikan informasi mengenai dirinya bila topik pembahasannya berkenaan dengan minat dan selera.

\section{SARAN}

Berdasarkan hasil temuan penelitian maka terdapat kelemahan penelitian ini tidak melihat perbedaan dari sisi jenis kelamin, sedangkan pada aspek self disclosure sangat dipengaruhi oleh jenis kelamin. Kemudian penelitian lanjutan yang sangat disarankan pada temuan ini ialah pentingnya peningkatan keterampilan self disclosure pada mahasiswa khususnya mahasiswa bimbingan dan konseling islam. Hal ini karena keterampilan self disclosure sangat diperlukan dalam proses konseling.

\section{DAFTAR PUSTAKA}

Arlett, C., Little, B. R., \& Best, J. A. (1976). The Influence of Interviewer Self Disclosure and Verbal Reinforcement an Personality Tests. Journal of Clinical Psychology. 32 (4): 770-774.

Baharuddin. (2008). Paradigma Psikologi Islami. Study tentang elemen psikologi dari al-qur'an. Cirebon: pustaka Pelajar

Berry, J. W., Poortinga, Y. H., Segall, M. H., \& Dasen, P. H. (2002). Cross-Cultural Psychology: Research and applications. New York: Cambridge University Press.

Borae, J., \& Hyun-Joo, N. (2015). Self Disclosure Tendency, Facebook Activitas \& Relational Usefulness Sex Diffences in Young Aduls. The Journal of The Korea Contents Association. 15 (7): 449-459.

Chalidaziah, W. (2018). Self Disclosure Mahasiswa (Kajian dalam Budaya Melayu dan Aceh).

Corey, G. (2010). Teori dan Praktek Konseling $\mathcal{E}$ Psikoterapi. Bandung: Refika Aditama.

Cormier, W. H., \& Cormier, L. S. (1991). Interviewing Strategies for Helpers: Fundamental skills and cognitive behavioral interventions. Canada: Wadsworth.

Daharnis., Nirwana, H., Ilyas, A., \& Karneli, Y. (2001). Pengungkapan Diri (Self Disclosure) Mahasiswa Universitas Negeri Padang (UNP). Jurnal Ilmu Pendidikan, 8 (3): 294-304.

DeVito, J. A. (2012). The Interpersonal Communication Book (13th Edition). New York: Pearson. 
Franzoi, S. L. (2003). Social Psychology. New York: McGraw-Hill Companies, Inc

Gladding, S. T. (2012). Konseling: Profesi yang menyeluruh. Jakarta: Kencana.

Hargie, O. (2011). Skilled Interpersonal Communication: Research, theory, and practice. London and New York: Routledge Taylor and Francis Group.

Horne, R. M \& Matthew, D. J. (2017). Gender Role Attitudes, Relationship Efficacy and Self Disclosure in Intimate Relationships. The Journal of Social Psychology. 158 (1): 37-50.

Ifdil. (2013). Konsep Dasar Self Disclosure dan Pentingnya Bagi Mahasiswa Bimbingan dan Konseling. Jurnal Ilmiah Ilmu Pendidikan.13 (1): 110-117.

Ifdil., Ardi, Z., Bariyah, K., Hariko, K., \& Solina, W. (2013). Tingkat self disclosure mahasiswa bimbingan dan konseling. Prosiding Konvensi Nasional BK XVIII. Denpasar Bali, 14 s/d 16 November 2013. Profesi Konseling Bermartabat dalam Masyarakat Multikultural dan Modern.

Jourard, S. M. (1974). Healthy Personality: An approach from the viewpoint of humanistic psychology. Canada: Macmillan.

Jourard, S. M., \& Lasakow, P. (1985). Some Factor in Self Disclosure. Journal of Abnormal and Social Psychology. 56 (1): 91-98.

Jourard, S. M., \& Richman, P. (1963). Factor in The Self Disclosure Input of Collage Students. Merrill-Palmer Quarterly of Behavior and Development. 9 (2): 141-148.

Michener, H. A. \& DeLamater, J. D. (1999). Social Psychology. Sea Harbor Drive,
Orlando, Philadelphia: Harcourt Brance \& Company.

Miller, R. S. (2015). Intimate Relationships. Seventh edition. USA: Mc Graw Hill.

Mulyana, D. (2009). Ilmu Komunikasi. Suatu pengantar. Bandung: Remaja Rosda Karya

Myers, D. G. (2012). Psikologi Sosial Jilid 2. Alih Bahasa. Aliya, T., Lala, S. S., Petty, G. G., \& Puti, N.G. Jakarta: Salemba Humaika.

Nelson-Jones, R. (2011). Teori dan Praktik Konseling dan Terapi. Yogyakarta: Pustaka Belajar.

Nirwana, H. (2012). Pengungkapan Diri Siswa Sekolah Menengah dan Implikasinya bagi Konseling. Jurnal Ilmu Pendidikan. 18 (1): 1-17.

Ponzetti, J. J. (1990). Loneliness Among College Students. National Council on Family Relations. 39(3): 336-340.

Samovar, L. A., Porter, R. E., \& McDaniel, E. R. (2010). Komunikasi Lintas Budaya. Alih bahasa. MS, Indri. Jakarta: Salemba Humanika.

Sari, R., Rejeki, T., \& Mujab, A. (2006). Pengungkapan Diri Mahasiswa Tahun Pertama Universitas Diponegoro Ditinjau dari Jenis Kelamin dan Harga Diri. Jurnal Psikologi Universitas Diponegoro, 3 (2): 11-25.

Siagian, K. (2016). Pengungkapan Diri Klien dalam Konseling Perorangan. Tesis tidak diterbitkan. Padang: Program Pascasarjana. Universitas Negeri Padang.

Sudjiman, P. H. M. (1996). Adat Raja-Raja Melayu. Jakarta: Universitas Indonesia Press. 
Sasaran dan Topik .... Wan Chalidaziah

Sutoyo, A. (2014). Bimbingan dan Konseling Islami (Teori \& praktik). Yogyakarta: Pustaka Belajar.

Suwardi. (2008). Dari Melayu ke Indonesia: Peranan kebudayaan melayu dalam memperkokoh identitas dan jati diri bangsa. Yogyakarta: Pustaka Pelajar.

Tang, N., Bensman, L., \& Haffield, E. (2013). Culture and Sexual Self Disclosure in Intimate Relationships. Interpersona. 7 (2): 227-245.

Taylor, S. E., Peplau, L. A \& Sears, D. O. (2006). Social Psychology. New Jersey: Person Pentice Hall.

Triandis, H. C. (1994). Culture and Social Behavior. Amerika: McGraw-Hill.

Utz, Sonja. (2015). The Function of Self Disclosure on Social Network Sites: Not only intimate, but also positive and entertaining self-disclosures increase the feeling of connection. Computers in Human Behaviors. 45 (2015): 1-10.

Wei, M., Ressell, D. W., \& Zakalik, R. A. (2005). Adult Attachment, Social SelfEfficacy, Self-Disclosure, Loneliness, and Subsequent Depression for Freshman College Students: A longitudinal study. Journal of Counseling Psychology. 52 (4): 602-614.. 